\title{
Soil hydraulic conductivity as affected by vegetation restoration age on the Loess Plateau, China
}

\author{
REN Zongping ${ }^{1,2^{*}}$, ZHU Liangjun ${ }^{3}$, WANG Bing ${ }^{2}$, CHENG Shengdong ${ }^{2}$ \\ ${ }^{1}$ State Key Laboratory Base of Eco-Hydraulic Engineering in Arid Area, Xi'an University of Technology, Xi'an 710048, China; \\ ${ }^{2}$ State Key Laboratory of Soil Erosion and Dryland Farming on Loess Plateau, Institute of Soil and Water Conservation, \\ Chinese Academy of Science, Yangling 712100, China; \\ ${ }^{3}$ State Key Laboratory of Resources and Environmental Information System, Institute of Geographic Sciences and Natural \\ Resources Research, Chinese Academy of Sciences, Beijing 100101, China
}

\begin{abstract}
The Loess Plateau of China has experienced extensive vegetation restoration in the past several decades, which leads to great changes in soil properties such as soil bulk, porosity, and organic matter with the vegetation restoration age. And these soil properties have great effect on the soil infiltration and soil hydraulic conductivity. However, the potential changes in soil hydraulic conductivity caused by vegetation restoration age have not been well understood. This study was conducted to investigate the changes in soil hydraulic conductivity under five grasslands with different vegetation restoration ages $(3,10,18,28$ and 37 years) compared to a slope farmland, and further to identify the factors responsible for these changes on the Loess Plateau of China. At each site, accumulative infiltration amount and soil hydraulic conductivity were determined using a disc permeameter with a water supply pressure of $-20 \mathrm{~mm}$. Soil properties were measured for analyzing their potential factors influencing soil hydraulic conductivity. The results showed that the soil bulk had no significant changes over the initial 20 years of restoration $(P>0.05)$; the total porosity, capillary porosity and field capacity decreased significantly in the grass land with 28 and 37 restoration ages compared to the slope farmland; accumulative infiltration amount and soil hydraulic conductivity were significantly enhanced after 18 years of vegetation restoration. However, accumulative infiltration amount and soil hydraulic conductivity fluctuated over the initial 10 years of restoration. The increase in soil hydraulic conductivity with vegetation restoration was closely related to the changes in soil texture and structure. Soil sand and clay contents were the most influential factors on soil hydraulic conductivity, followed by bulk density, soil porosity, root density and crust thickness. The Pearson correlation coefficients indicated that the soil hydraulic conductivity was affected by multiply factors. These results are helpful to understand the changes in hydrological and erosion processes response to vegetation succession on the Loess Plateau.
\end{abstract}

Keywords: disc permeameter; effect factors; soil infiltration; vegetation restoration; Loess Plateau

Citation: REN Zongping, ZHU Liangjun, WANG Bing, CHENG Shengdong. 2016. Soil hydraulic conductivity as affected by vegetation restoration age on the Loess Plateau, China. Journal of Arid Land, 8(4): 546-555. doi: 10.1007/s40333-016-0010-2

Soil infiltration is a critical process of the hydrological cycle in terrestrial ecosystems and it is the crucial link between the precipitation and soil water storage (Ludwig et al., 2005; Zhao et al., 2013). As a fundamental hydrological process, soil hydraulic conductivity has a direct effect on the water budget of an ecosystem, the amount of surface runoff and the associated risk of substantial erosion (Michaelides et al., 2009; Chartier et al., 2011). Therefore, analyzing the

\footnotetext{
*Corresponding author: REN Zongping (E-mail: renzongping@163.com)

Received 2015-09-13; revised 2016-02-21; accepted 2016-02-29

(C) Xinjiang Institute of Ecology and Geography, Chinese Academy of Sciences, Science Press and Springer-Verlag Berlin Heidelberg 2016
} 
process of soil infiltration and its effect factors are important for understanding and modeling the hydrological cycle of terrestrial ecosystems ( $\mathrm{Li}$ et al., 2011).

Under similar climatic and topographic conditions, soil infiltration is mainly controlled by soil properties. Soil infiltration increases with increasing soil sand content, soil porosity, aggregate size and soil organic matter, and decreases with increasing soil bulk density, soil clay content and initial soil water content (Zhou et al., 2008; Neris et al., 2012; Zhao et al., 2014). Any activities that change soil properties can critically affect the soil hydraulic conductivity. For example, Neris et al. (2012) reported that soil infiltration and soil hydraulic conductivity were significantly affected by soil aggregation, structural stability, organic matter and bulk density. Gonzalez-Sosa et al. (2010) found that hydraulic properties would enhance after the conversion of a farmland or a pasture to a forestland due to high soil organic matter accumulation, root system density and soil fauna activity, which lead to an increased soil macro-porosity and decreased soil bulk density. Conversely, Price et al. (2010) showed that the hydraulic properties decreased after a forest was converted to a non-forest because soil compaction associated with land management practices. Moreover, Nyberg et al. (2012) reported that soil infiltrability decreased with time after a forest was converted to a cropland, with decreased in soil carbon and nitrogen and increased soil bulk density.

The Loess Plateau of China covers an area of $6.4 \times 10^{5} \mathrm{~km}^{2}$, and it is a region with the most severely erosion (Shi and Shao, 2000). Since the 1950s, a number of soil conservation measures (e.g. check-dam construction, afforestation and restoration of natural vegetation) have been taken to control soil erosion in this region (Chen et al., 2007). Among these measures, abandoning the steep slope farmland to natural succession has become one of the most widely used techniques on the Loess Plateau (Jiao et al., 2007). In 1999, the Grain-for-Green project was undertaken by the Chinese central government to mitigate soil and water losses (Zhang et al., 2008; Li and Lu, 2015). As a result, a vast area of steep slope farmland has been converted into grassland and forestland or abandoned for natural succession, which resulted in a $10.8 \%$ area decrease in the slope farmland on the Loess Plateau between 2000 and 2008 (Lü et al., 2012).

Generally, vegetation restoration has a positive impact on soil properties due to increased vegetation cover and accumulation of plant litters. Many studies have indicated that soil organic matter and total nitrogen, soil porosity and aggregate stability increased while soil bulk density and $\mathrm{pH}$ decreased after a farmland was converted to a forest or a grassland (Li and Shao, 2006; Wang et al., 2011; Neris et al., 2012). Li and Shao (2006) reported that soil organic matter increased from 7.6 to $21.3 \mathrm{~g} / \mathrm{kg}$, and total porosity and capillary porosity increased from $51.4 \%$ to $62.7 \%$ and $41.7 \%$ to $50.1 \%$, respectively. The initial and steady saturated conductivity increased from 0.12 to 0.55 and 0.05 to $0.24 \mathrm{~mm} / \mathrm{min}$. Soil bulk density decreased from 1.29 to $0.99 \mathrm{~g} / \mathrm{cm}^{3}$ after farmland was abandoned for 150 years. Wang et al. (2011) found that soil organic C and total $\mathrm{N}$, soil microbial biomass $\mathrm{C}$ and $\mathrm{N}$ as well as alkaline phosphatase, catalase, saccharase and cellulose activities increased, while soil bulk density, $\mathrm{pH}$ and polyphenol oxidase activity decreased after a farmland was abandoned for 50 years. However, some studies reported the adverse effects of vegetation restoration on soil properties. For example, Jiao et al. (2011) reported that soil nutrition, such as soil organic matter and total nitrogen decreased during the early stage of vegetation restoration after farmland abandonment on the Loess Plateau. Wang et al. (2009) found that tree planting on a former farmland caused an obvious decline in soil water content and led to the formation of a dried soil layer in the arid area.

As mentioned above, changes in soil properties may significantly influence soil infiltration. Studies have found that vegetation restoration can reduce surface runoff and increase soil hydraulic conductivity, and that annual reduction in runoff increases with the vegetation area and with restoration age (Zhang et al., 2008; Wang et al., 2011). The Loess Plateau of China has experienced extensive vegetation restoration in the past decades. Previous studies have paid great attention on the changes in soil water storage, soil nutrition and soil quality in this region related to the vegetation restoration on abandoned slope farmland (Wang et al., 2009; Chen et al., 2010; Jiao et al., 2011; Wang et al., 2011). However, few studies have been conducted to investigate the changes in soil infiltration based on vegetation restoration age on the Loess Plateau. Therefore, the 
objectives of this study were to investigate the changes in soil hydraulic conductivity of natural successional grasslands with different vegetation restoration ages, and further to identify factors that influenced the changes of soil hydraulic conductivity in this region on the Loess Plateau of China.

\section{Materials and methods}

\subsection{Study area}

This study was conducted in Zhifanggou, a small watershed of Ansai county near the center of the Loess Plateau, China (Fig. 1). The watershed has a total drainage area of $8.27 \mathrm{~km}^{2}$ and elevations that range from 1,068 to $1,309 \mathrm{~m}$. It is a typical gully and hilly area with a slope gradient that varies from $0^{\circ}$ to $65^{\circ}$. This region has a semi-arid continental climate with annual mean temperature of $8.8^{\circ} \mathrm{C}$ and mean annual precipitation of $505 \mathrm{~mm}$. The soil type is silt loam which is vulnerable to water erosion (Wang et al., 2013).

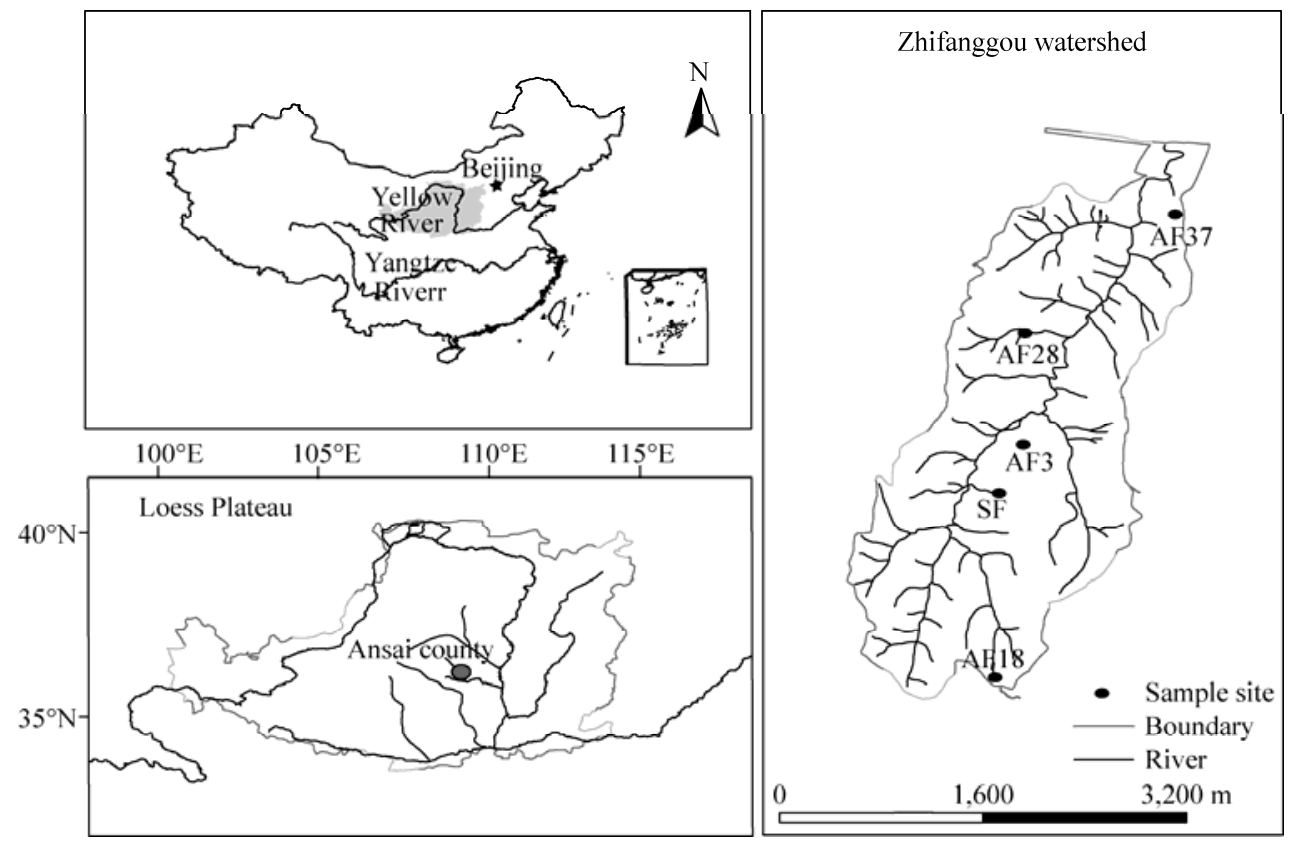

Fig. 1 Locations of the study sites in the Zhifanggou watershed on the Loess Plateau of China

Since 1975, the Zhifanggou has been used as a pilot watershed in the Loess Plateau for vegetation restoration and construction initiatives for soil and water conservation. Especially after implementation of Grain-for-Green project in 1999, most of the steep slope farmland was abandoned for natural vegetation or converted to artificial grassland and forestland. The restoration age of the abandoned farmland in this watershed is relatively clear and reliable. The dominant forest species in this area are Robinia pseudoacacia, Populus simonii and Platycladus orientalis, the dominant shrub species are Caragana microphylla, Hippophae rhamnoides and Sophora viciifolia and the dominant grassland species are Artemisia sacrorum, Stipa bungeana and Artemisia capillaries.

\subsection{Site selection}

As shown in Fig. 1, six sites were selected in Zhifanggou watershed for quantifying the influence of vegetation restoration age on the soil infiltration. Five of the sites were abandoned farmlands; the corresponding abandonment ages were 3, 10, 18, 28 and 37 years. A slope farmland planted with soybean was selected as a control. For minimizing the potential influence of site selection on experimental results, all six selected sites have similar elevation, slope aspect, gradient and shape. The basic information of the selected sites is shown in Table 1. 
Table 1 Basic information of the selected sites for infiltration measurement on the Loess Plateau of China

\begin{tabular}{cccccl}
\hline Sites & Slope $\left(^{\circ}\right)$ & Aspect & Elevation $(\mathrm{m})$ & Vegetative coverage $(\%)$ & Dominant communities \\
\hline SF & 8.7 & Semi-sunny & 1,194 & 38.9 & Giycine max \\
AF3 & 14.0 & Semi-sunny & 1,184 & 42.3 & Achillea capillaries \\
AF10 & 12.2 & Semi-shady & 1,089 & 40.9 & $\begin{array}{l}\text { Achillea capillaris }+ \text { Artemisia } \\
\text { sacrorum }\end{array}$ \\
AF18 & 14.0 & Semi-shady & 1,342 & 56.1 & Artemisia sacrorum + Stipa bungeana \\
AF28 & 17.5 & Semi-shady & 1,167 & 60.0 & Artemisia sacrorum + Stipa bungeana \\
AF37 & 10.5 & Semi-shady & 1,213 & 60.7 & Stipa bungeana + Artemisia sacrorum \\
\hline
\end{tabular}

Note: SF, slop farmland; AF3, AF10, AF18, AF28 and AF37 refer to abandoned farmland age of 3, 10, 18, 28 and 37 years, respectively. The following abbreviations are the same.

\subsection{Disc experiment and determination of hydraulic conductivity}

On each selected site, a set of soil infiltration test was carried out using a CSIRO disc permeameter (Center for Environmental Mechanics, Canberra, Australia). Before the experiment, plant was carefully clipped with scissors and was swept away with a soft brush. The testing area was covered with fine sand $(0.25 \mathrm{~mm}$ in diameter) for a depth of $1 \mathrm{~mm}$. Then the disc permeameter was then installed. After the pressure head of water supply was adjusted to $-20 \mathrm{~mm}$ and the measurement was started. Time intervals were $0.5,2$ and $5 \mathrm{~min}$ for the first 10 readings, the following 5 readings and the remaining readings, respectively. The experiment ran for 90 minutes. Water temperature was measured simultaneously. At each site, soil infiltration tests were done for four replicates. The cumulative infiltration was calculated as follows:

$$
I=\sum_{t=1}^{n} \frac{\Delta h_{n} D_{2}^{2}}{D_{1}^{2}(0.7+0.03 T)} .
$$

Where $I(\mathrm{~mm})$ is the cumulative infiltration amount at $10^{\circ} \mathrm{C}$ standard water temperature; $\Delta h_{n}(\mathrm{~mm})$ is the drop height of reservoir for a certain time; $D_{1}(\mathrm{~mm})$ is the diameter of permeameter disk $(200 \mathrm{~mm}) ; D_{2}(\mathrm{~mm})$ is the diameter of water reservoir $(47 \mathrm{~mm})$ and $T\left({ }^{\circ} \mathrm{C}\right)$ is the water temperature at the measurement.

Hydraulic conductivity was calculated by the single test method (Vandervaere, 2000). The equation is the following:

$$
K=\frac{3}{2-\beta}\left[C_{2}-\frac{\gamma C_{1}^{2}}{R\left(\theta_{0}-\theta_{n}\right)}\right]
$$

Where $K$ is soil hydraulic conductivity; $\gamma$ is a constant equal to $0.75 ; R(\mathrm{~mm})$ is the disk radius; $\beta$ is a constant of 0.6 , which was acceptable for a filed estimation; $\theta_{n}$ and $\theta_{0}$ are the initial volumetric water content and the surface boundary conditions, respectively. $C_{1}$ and $C_{2}$ are two variables, established as follow:

$$
\frac{d I}{d \sqrt{t}}=C_{1}+C_{2} \sqrt{t}
$$

Where $I(\mathrm{~mm})$ is the cumulative infiltration. Equation 3 was developed from the Philips equation by Vandervaere et al. (2000).

\subsection{Measurements of soil properties}

Soil properties were measured at each site for identifying potential factors impacting the soil infiltration process. Biological crust thickness was measured using calipers with 10 replications at each site. Three intact soil samples were collected from top soil at each site with a steel ring $(5 \mathrm{~cm}$ in diameter and $5 \mathrm{~cm}$ in depth) for measuring soil bulk density, field capacity, capillary porosity and total porosity. The collected samples were first wetted $5 \mathrm{~mm}$ deep with water for six hours and weighed to measure capillary porosity. They were then wetted $50 \mathrm{~mm}$ deep with water for $12 \mathrm{~h}$ 
and weighed to determine the total porosity. The samples were drained for $48 \mathrm{~h}$ to measure field capacity and finally dried for $24 \mathrm{~h}$ at $105^{\circ} \mathrm{C}$ to determine soil bulk density. For measuring soil water stable aggregate, we placed $50 \mathrm{~g}$ of each soil sample on a nest of sieves with apertures measuring $0.25,0.5,1.0,2.5$ and $5.0 \mathrm{~mm}$, submerged in water, and shaken vertically at a rate of 30 times per minute. The large water stable aggregates remaining on the sieves $(>0.25 \mathrm{~mm})$ were oven dried for $24 \mathrm{~h}$ at $105^{\circ} \mathrm{C}$, weighed and calculated. These aggregates measurements were replicated three times. Plant roots were isolated from the known volume soil samples taken from each site, washed over a 2-mm sieve, oven dried at $65^{\circ} \mathrm{C}$ for $12 \mathrm{~h}$ and weighed to compute root mass density. Three replicates of root mass density were measured. Across each site, six samples from the top $20 \mathrm{~cm}$ of soil layer were collected in an S-shaped pattern. These samples were mixed well and air-dried. Each combined sample was sieved through a 2-mm mesh with roots and debris removed by hand. These soil samples were used for analyzing soil particle size distribution using hydrometer method (Ashworth et al., 2001) and soil organic matter using the potassium dichromate colorimetric method. The measured soil properties of each site are shown in Table 2.

Table 2 Soil properties of six testing sites

\begin{tabular}{cccccccc}
\hline Site & Clay (\%) & Silt (\%) & Sand (\%) & $\begin{array}{c}\text { Water stable } \\
\text { aggregate }(\%)\end{array}$ & $\begin{array}{c}\text { Soil organic } \\
\text { matter }(\mathrm{g} / \mathrm{kg})\end{array}$ & $\begin{array}{c}\text { Crust thickness } \\
(\mathrm{mm})\end{array}$ & $\begin{array}{c}\text { Root density } \\
\left(\mathrm{kg} / \mathrm{m}^{3}\right)\end{array}$ \\
\hline SF & 16.0 & 63.8 & 20.2 & 29.0 & 7.96 & 0.00 & 0.29 \\
AF3 & 16.0 & 57.9 & 216.2 & 32.8 & 5.59 & 2.99 & 1.12 \\
AF10 & 15.9 & 61.7 & 22.3 & 53.2 & 8.78 & 1.95 & 4.35 \\
AF18 & 11.9 & 59.7 & 28.4 & 41.0 & 7.12 & 1.56 & 2.82 \\
AF28 & 10.0 & 63.8 & 26.2 & 17.7 & 7.86 & 1.97 & 4.18 \\
AF37 & 12.0 & 59.7 & 28.3 & 54.1 & 10.72 & 1.35 & 6.35 \\
\hline
\end{tabular}

\subsection{Statistical analysis}

One-way analysis of variance (ANOVA) was used to test the significant difference in cumulative infiltration amount and soil hydraulic conductivity between different restoration ages. Principal component analysis (PCA) was used to analyze the main factors influencing the soil infiltration process. The relationships between infiltration parameters and soil properties were determined by Spearman correlation analysis. All analyses were performed using SPSS software version 18.0.

\section{Results}

\subsection{Soil properties of different vegetation restoration ages}

The measured soil bulk density of abandoned slope farmlands did not vary significantly from the slope farmland control site regardless of restoration age; it generally showed little change over 20 years following restoration. However, total porosity was consistent: after 3 and 18 years of restoration, total porosity showed no significant change; after 10 years of restoration, total porosity decreased significantly, and in the 37 years of abandoned slope farmlands, total porosity was significantly higher. Capillary porosity and field capacity had trends similar to the total porosity with restoration age. And these three soil properties had a fluctuation change with the restoration age.

Table 3 Soil bulk density, total porosity, capillary porosity and field capacity with restoration vegetation ages

\begin{tabular}{lcccccc}
\hline Item & SF & AF3 & AF10 & AF18 & AF28 & AF37 \\
\hline Soil bulk density $\left(\mathrm{g} / \mathrm{cm}^{3}\right)$ & $1.25 \pm 0.04^{\mathrm{ab}}$ & $1.19 \pm 0.02^{\mathrm{c}}$ & $1.27 \pm 0.03^{\mathrm{a}}$ & $1.24 \pm 0.14^{\mathrm{ac}}$ & $1.19 \pm 0.00^{\mathrm{bc}}$ & $1.19 \pm 0.02^{\mathrm{bc}}$ \\
Total porosity (\%) & $47.29 \pm 1.08^{\mathrm{a}}$ & $49.78 \pm 0.76^{\mathrm{ab}}$ & $32.65 \pm 1.27^{\mathrm{c}}$ & $50.53 \pm 0.84^{\mathrm{ab}}$ & $35.82 \pm 6.10^{\mathrm{c}}$ & $53.21 \pm 0.45^{\mathrm{bd}}$ \\
Capillary porosity (\%) & $45.37 \pm 0.81^{\mathrm{a}}$ & $47.95 \pm 0.50^{\mathrm{ab}}$ & $26.25 \pm 0.38^{\mathrm{c}}$ & $47.77 \pm 0.79^{\mathrm{bd}}$ & $27.70 \pm 3.44^{\mathrm{c}}$ & $47.74 \pm 0.25^{\mathrm{ad}}$ \\
Field capacity (\%) & $36.41 \pm 2.57^{\mathrm{a}}$ & $39.70 \pm 2.15^{\mathrm{ab}}$ & $20.79 \pm 0.62^{\mathrm{c}}$ & $40.29 \pm 0.72^{\mathrm{bd}}$ & $23.41 \pm 2.87^{\mathrm{c}}$ & $40.43 \pm 1.36^{\mathrm{bd}}$ \\
\hline
\end{tabular}

Note: Values in the same column followed by the same letter are not significantly different at $P<0.05$ level. Mean \pm SD. 


\subsection{Changes in hydraulic conductivity with vegetation restoration ages}

Figure 2 showed that the cumulative infiltration amounts had significant difference under different vegetation restoration ages, which changed slowly in the early 10 years of natural vegetation restoration, and then significantly increased after 18 years of restoration. The cumulative infiltration amounts were obviously higher in sites AF18, AF28 and AF37 of the late restoration stages than those of the early restoration stages. The cumulative infiltration amounts remained stable after 18 years vegetation restoration with an average value of $44.5 \mathrm{~mm}$. Hydraulic conductivity was found to fluctuate after 20 years of abandonment, while the change trends were similar with the cumulative infiltration. The value of the hydraulic conductivity was from 0.44 (SF) to $1.34 \mathrm{~mm} / \mathrm{min}$ (AF28). Generally, soil hydraulic conductivity showed a trend of increasing with vegetation restoration age (Fig. 3). There is a statistically significant difference in soil hydraulic conductivity after 18 years of restoration when compared with the SF slope farmland and the 10 years of restoration. No statistical difference was found between study areas of AF18, AF28 and AF37.

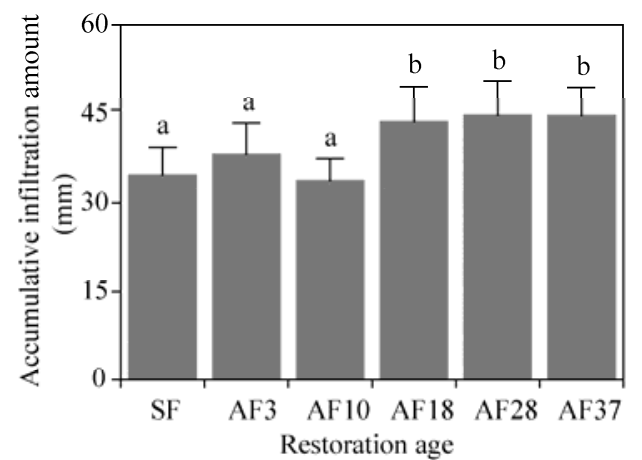

Fig. 2 Variation of cumulative infiltration amount under different vegetation restoration ages. Different lowercase letters indicate significant difference at $P<0.05$ level under different vegetation restoration ages in 90-min cumulative infiltration amount.

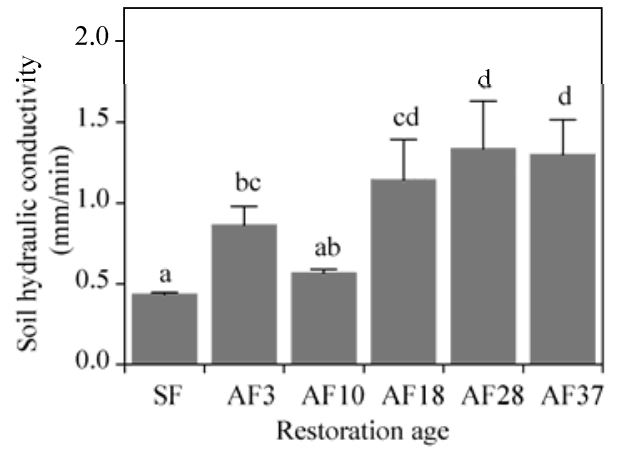

Fig. 3 Soil hydraulic conductivity under different vegetation restoration ages. Different lowercase letters indicate significant difference at $P<0.05$ level under different vegetation restoration ages. $n=4$.

\subsection{Relationships between infiltration parameters and soil properties}

We used Principal Component Analysis (PCA) for classifying 11 soil properties. Three components together explained $87.5 \%$ of the total variance $(46.6 \%, 23.4 \%$ and $17.5 \%$ for PCA components 1, 2 and 3, respectively) (Table 4). The PCA component 1 correlated with the soil properties of clay and sand content, porosity, field capacity, root density and bulk density, which indicates that soil texture and structure are the main factors affecting soil infiltration (Table 5). The PCA component 2 reflects the combined effect of silt content, soil organic matter and crust thickness on soil infiltration. The PCA component 3 can be interpreted as the influence of water stable aggregation on infiltration process (Table 5).

Table 6 showed correlations among soil properties and hydraulic conductivity. In general, soil hydraulic conductivity had significantly positive correlation with the sand content, total porosity, capillary porosity and root density $(P<0.05)$. However, there was a significantly negative correlation between soil hydraulic conductivity and clay content and bulk density $(P<0.05)$. Moreover, the Pearson correlation coefficients of those six soil factors were all greater than 0.6 , which indicated that hydraulic conductivity was affected by multiple factors.

Table 4 Eigenvalues and variance of the first three PCA components

\begin{tabular}{cccc}
\hline Item & Eigenvalues & Percent of variation (\%) & Cumulative percent of variation (\%) \\
\hline Component 1 & 5.13 & 46.6 & 46.6 \\
Component 2 & 2.57 & 23.4 & 70.0 \\
Component 3 & 1.93 & 17.5 & 87.5 \\
\hline
\end{tabular}


Table 5 Correlations between soil properties and the first three PCA components

\begin{tabular}{lccc}
\hline Soil property & Component 1 & Component 2 & Component 3 \\
\hline Clay & -0.871 & 0.215 & 0.346 \\
Silt & -0.186 & -0.811 & -0.495 \\
Sand & 0.833 & 0.425 & 0.089 \\
BD & -0.761 & 0.336 & 0.249 \\
TP & 0.890 & -0.265 & -0.093 \\
CP & 0.774 & 0.476 & -0.043 \\
WSA & 0.111 & -0.023 & 0.983 \\
FC & 0.854 & 0.065 & -0.226 \\
SOM & 0.337 & 0.775 & 0.524 \\
CT & 0.398 & -0.742 & -0.008 \\
RD & 0.809 & -0.349 & 0.434 \\
\hline
\end{tabular}

Note: BD, bulk density; TP, total porosity; CP, capillary porosity; WSA, water stable aggregate; FC, field capacity; SOM, soil organic matter; CT, crust thickness; RD, root density. The following abbreviations are the same.

Table 6 Correlations between infiltration parameters and soil properties

\begin{tabular}{|c|c|c|c|c|c|c|c|c|c|c|c|c|}
\hline Variable & Clay & Silt & Sand & $\mathrm{BD}$ & TP & $\mathrm{CP}$ & WSA & $\mathrm{FC}$ & SOM & $\mathrm{CT}$ & $\mathrm{RD}$ & $\mathrm{K}$ \\
\hline Clay & 1.000 & & & & & & & & & & & \\
\hline Silt & -0.154 & 1.000 & & & & & & & & & & \\
\hline Sand & $-0.686^{* *}$ & $-0.614^{* *}$ & 1.000 & & & & & & & & & \\
\hline $\mathrm{BD}$ & $0.853^{* *}$ & -0.131 & $-0.585^{* *}$ & 1.000 & & & & & & & & \\
\hline TP & $-0.795^{* *}$ & 0.181 & $0.502^{* *}$ & $-0.643^{* *}$ & 1.000 & & & & & & & \\
\hline $\mathrm{CP}$ & $-0.697^{* *}$ & $-0.527^{* *}$ & $0.946^{* *}$ & $-0.436^{*}$ & $0.494^{* *}$ & 1.000 & & & & & & \\
\hline WSA & 0.233 & $-0.459^{* *}$ & 0.152 & 0.218 & 0.045 & 0.056 & 1.000 & & & & & \\
\hline $\mathrm{FC}$ & -0.047 & 0.108 & -0.041 & -0.035 & $0.577^{* *}$ & -0.121 & $-0.657^{* *}$ & 1.000 & & & & \\
\hline SOM & -0.282 & 0.280 & 0.020 & $-0.439^{*}$ & $0.425^{*}$ & -0.136 & $0.556^{* *}$ & $0.695^{* *}$ & 1.000 & & & \\
\hline $\mathrm{CT}$ & -0.042 & $-0.606^{* *}$ & $0.479^{* *}$ & 0.026 & 0.302 & $0.449^{*}$ & 0.013 & 0.120 & $-0.457^{*}$ & 1.000 & & \\
\hline $\mathrm{RD}$ & $-0.578^{* *}$ & -0.057 & $0.504^{* *}$ & $-0.589^{* *}$ & $0.825^{* *}$ & $0.370^{*}$ & $0.525^{* *}$ & $0.780^{* *}$ & $0.765^{* *}$ & 0.160 & 1.000 & \\
\hline $\mathrm{K}$ & $-0.911^{* *}$ & -0.230 & $0.897^{* *}$ & $-0.851^{* *}$ & $0.729^{* *}$ & $0.830^{* *}$ & -0.087 & 0.029 & 0.188 & 0.331 & $0.618^{* *}$ & 1.000 \\
\hline
\end{tabular}

Note: K, hydraulic conductivity. ${ }^{*}$ and ${ }^{* *}$ indicate the significant difference at $P<0.05$ and $P<0.01$ levels, respectively.

\section{Discussion}

\subsection{Changes in soil hydraulic conductivity under different vegetation restoration age}

In the present study, soil hydraulic conductivity was significantly enhanced after slope farmland was abandoned for 18 years. Soil hydraulic conductivity generally increased with the years of abandonment (Fig. 3). Results are consistent with previous studies that soil infiltration capacity was enhanced after vegetation restoration (Chartier et al., 2011; Yüksek and Yüksek, 2011; Zhao et al., 2013). The enhancement of soil infiltration capacity is mainly associated with vegetation growth and improvement in soil properties (Li et al., 2011; Neris et al., 2012). In this study, vegetation cover increased from $38.9 \%$ in farmland to $60.7 \%$ in 37 -year abandoned grassland (Table 1), and root mass density increased from 0.29 to $6.35 \mathrm{~kg} / \mathrm{m}^{3}$ (Table 2). These changes led to an increase in the soil organic matter and the promotion of soil structure. Thus, soil porosity and water aggregate stability increased, while bulk density decreased over time during vegetation restoration. Moreover, the generation of macropores and channels by root penetration through soil tends to form preferential flow paths, thus enhancing soil infiltration and reducing runoff and soil erosion (Li et al., 2011; Benegas et al., 2014).

However, the fluctuations of soil hydraulic conductivity were found to be associated with the first 10 years of restoration (Fig. 3). Some studies have attributed these fluctuations to soil compaction and surface seal formation caused by raindrop impact (King and Bjorneberg, 2012; Liu et al., 2012; Zhao et al., 2014). This explanation is partially supported by our result that soil 
bulk density was slightly higher at site AF10 than at the slope farmland site (Table 3 ). We infer that the spatial heterogeneity of vegetation and soil properties play an important role in this fluctuation of soil infiltration in the first 10 years of restoration. After the farmland was abandoned, all tillage operations were stopped. Annual and perennial herbs grew randomly and formed patchy distribution patterns. The spatial heterogeneity of vegetation and soil properties was obvious in the early restoration stage because vegetation cover was relatively limited. A previous study reported a similar finding whereby spatial heterogeneity of soil properties had increased in the first 10 years of vegetation restoration and then decreased from 11 to 20 years due to the continuous development of vegetation (Zuo et al., 2009).

\subsection{Factors impacting the soil infiltration process}

Vegetation restoration enhances soil hydraulic conductivity through direct interactions of soil properties and vegetation (Yüksek and Yüksek, 2011; Neris et al., 2012). Our PCA results indicated that soil texture and structure were the main factors influencing soil infiltration (Table 5). The correlation analysis among infiltration parameters and soil properties further supports these conclusions (Table 6).

In this study, sand and clay contents of soil were found to be the most influential factors affecting soil hydraulic conductivity, followed by bulk density, soil porosity, root mass density and crust thickness (Table 6). Tejedor et al. (2013) found that infiltration was mainly determined by clay content and bulk density in soils without well-developed structure. Infiltration rate was fast in soils with more sand and less clay contents because soils enriched with sand had more large pores and were less likely to be compacted by trample; consequently, they had high hydraulic conductivity (Chartier et al., 2011). In addition, sand has a lower viscosity coefficient and soil water suction than do clay and silt, even when pore sizes are similar, which leads to higher infiltration rates in sandy soils (Yang and Zhang, 2011).

Soil infiltration can be greatly affected by soil compaction (Liu et al., 2012). This process increases bulk density and decreases porosity, which can significantly reduce soil infiltration (Yang and Zhang, 2011). In the early restoration stage, with low vegetation cover, raindrops hit the ground directly and caused natural compaction, which increased bulk density and decreased porosity and hydraulic conductivity (Table 2). As succession continued, vegetation cover increased, and soil organic matter gradually accumulated. This organic matter then could facilitate the formation of soil aggregates and increased porosity. Consequently, soil bulk density decreased and soil hydraulic conductivity was enhanced (Tables 1 and 2). Similar results were found in previous studies (Yüksek and Yüksek, 2011; Neris et al., 2012).

Plant roots play an important role in soil moisture redistribution (Neumann and Cardon, 2012). Both decayed and live roots can provide avenues for macropores associated with root channels (Devitt and Smith, 2002). It was found that more than $90 \%$ of water in clay-enriched soils flowed through root channels, while less than $10 \%$ flowed along fractures without root channels (Jørgensen et al., 2002). In our study, soil hydraulic conductivity closely correlated to root mass density $(P<0.05)$. This result agrees with the conclusions of Lange et al. (2009), who found that high root densities resulted in densely branched networks of pores and enhanced soil infiltrability.

The effect of biological crust on infiltration has remained ambiguous. Soil hydraulic conductivity could be increased (Belnap et al., 2005; Li et al., 2011), decreased (Ries and Hirt, 2008; Li et al., 2010) or unchanged (Williams et al., 1999) by the development of biological crusts. In our study, a significant negative relationship between biological crust thickness and soil hydraulic conductivity $(P<0.05)$ was detected (Table 6$)$. Biological crusts may prevent infiltration and increase surface runoff by forming an impermeable seal because of swelling of sheath material during imbibition (Li et al., 2011). The mechanical and hydraulic resistances may then increase after development of a biological crust with extended particle interlocking enhancing resistance (Bedaiwy, 2008). In addition, rainfall interception increases with crusts thickness, which would also reduce soil infiltration flux (Li et al., 2014). 


\section{Conclusions}

On the Loess Plateau, soil infiltration capacity was significantly enhanced after slope farmland was abandoned for 37 years. Soil hydraulic conductivity fluctuated within the first 10 years, increased rapidly from 10 to 18 years, and thereafter remained stable from 18 to 37 years of vegetation restoration. The increased soil infiltration capacity was mainly attributed to the increases in sand content, total porosity, capillary porosity of soil and root mass density, and the decreases in clay content, bulk density and biological crust thickness of soil. Sand and clay contents of soil were the most influential factors for the soil infiltration, followed by the soil bulk density and porosity, root mass density and biological crust thickness. These results are helpful to understand the changes in hydrological and erosion processes in response to vegetation succession on the Loess Plateau.

\section{Acknowledgements}

This work was funded by the by the State Key Program of National Natural Science of China (41330858), the National Natural Science Foundation of China (41471226) and the Open Foundation of State Key Laboratory of Soil Erosion and Dryland Farming on the Loess Plateau (A318009902-1510). The authors thank the members of the Ansai Station of the Institute of Soil and Water Conservation, Chinese Academy of Sciences and Ministry of Water Resource for their technical assistance.

\section{References}

Ashworth J, Keyes D, Kirk R, et al. 2001. Standard procedure in the hydrometer method for particle size analysis. Communications in Soil Science and Plant Analysis, 32(5-6): 633-642.

Bedaiwy M N A. 2008. Mechanical and hydraulic resistance relations in crust-topped soils. CATENA, 72(2): $270-281$.

Belnap J, Welter J R, Grimm N B, et al. 2005. Linkages between microbial and hydrologic processes in arid and semiarid watersheds. Ecology, 86(2): 298-307.

Benegas L, Ilstedt U, Roupsard O, et al. 2014. Effects of trees on infiltrability and preferential flow in two contrasting agroecosystems in Central America. Agriculture, Ecosystems \& Environment, 183: 185-196.

Chartier M P, Rostagno C M, Pazos G E. 2011. Effects of soil degradation on infiltration rates in grazed semiarid rangelands of northeastern Patagonia, Argentina. Journal of Arid Environments, 75(7): 656-661.

Chen L D, Wei W, Fu B J, et al. 2007. Soil and water conservation on the Loess Plateau in China: review and perspective. Progress in Physical Geography, 31(4): 389-403.

Chen L D, Wang J P, Wei W, et al. 2010. Effects of landscape restoration on soil water storage and water use in the Loess Plateau Region, China. Forest Ecology and Management, 259(7): 1291-1298.

Devitt D A, Smith S D. 2002. Root channel macropores enhance downward movement of water in a Mojave Desert ecosystem. Journal of Arid Environments, 50(1): 99-108.

Gonzalez-Sosa E, Braud I, Dehotin J, et al. 2010. Impact of land use on the hydraulic properties of the topsoil in a small French catchment. Hydrological Processes, 24(17): 2382-2399.

Jiao F, Wen Z M, An S S. 2011. Changes in soil properties across a chronosequence of vegetation restoration on the Loess Plateau of China. CATENA, 86(2): 110-116.

Jiao J Y, Tzanopoulos J, Xofis P, et al. 2007. Can the study of natural vegetation succession assist in the control of soil erosion on abandoned croplands on the Loess Plateau, China?. Restoration Ecology, 15(3): 391-399.

Jørgensen P R, Hoffmann M, Kistrup J P, et al. 2002. Preferential flow and pesticide transport in a clay-rich till: Field, laboratory, and modeling analysis. Water Resources Research, 38(11): 28-1-28-15.

King B A, Bjorneberg D L. 2012. Transient soil surface sealing and infiltration model for bare soil under droplet impact. Transactions of the ASABE, 55(3): 937-945.

Lange B, Lüescher P, Germann P F. 2009. Significance of tree roots for preferential infiltration in stagnic soils. Hydrology and Earth System Sciences, 13(10): 1809-1821.

Li W J, Lu C H. 2015. Aridity trend and response to vegetation restoration in the loess hilly region of northern Shaanxi Province. Journal of Geographical Sciences, 25(3): 289-300.

Li X R, Tian F, Jia R L, et al. 2010. Do biological soil crusts determine vegetation changes in sandy deserts? Implications for managing artificial vegetation. Hydrological Processes, 24(25): 3621-3630. 
Li X R, Gao Y H, Su J Q, et al. 2014. Ants mediate soil water in arid desert ecosystems: mitigating rainfall interception induced by biological soil crusts?. Applied Soil Ecology, 78: 57-64.

Li X Y, Contreras S, Solé-Benet A, et al. 2011. Controls of infiltration-runoff processes in Mediterranean karst rangelands in SE Spain. CATENA, 86(2): 98-109.

Li Y Y, Shao M A. 2006. Change of soil physical properties under long-term natural vegetation restoration in the Loess Plateau of China. Journal of Arid Environments, 64(1): 77-96.

Liu Y, Fu B J, Lü Y H, et al. 2012. Hydrological responses and soil erosion potential of abandoned cropland in the Loess Plateau, China. Geomorphology, 138(1): 404-414.

Lü Y H, Fu B J, Feng X M, et al. 2012. A policy-driven large scale ecological restoration: quantifying ecosystem services changes in the Loess Plateau of China. PLoS ONE, 7(2): e31782.

Ludwig J A, Wilcox B P, Breshears D D, et al. 2005. Vegetation patches and runoff-erosion as interacting ecohydrological processes in semiarid landscapes. Ecology, 86(2): 288-297.

Michaelides K, Lister D, Wainwright J, et al. 2009. Vegetation controls on small-scale runoff and erosion dynamics in a degrading dryland environment. Hydrological Processes, 23(11): 1617-1630.

Neris J, Jiménez C, Fuentes J, et al. 2012. Vegetation and land-use effects on soil properties and water infiltration of Andisols in Tenerife (Canary Islands, Spain). CATENA, 98: 55-62.

Neumann R B, Cardon Z G. 2012. The magnitude of hydraulic redistribution by plant roots: a review and synthesis of empirical and modeling studies. New Phytologist, 194(2): 337-352.

Nyberg G, Bargués Tobella A, Kinyangi J, et al. 2012. Soil property changes over a 120-yr chronosequence from forest to agriculture in western Kenya. Hydrology and Earth System Sciences, 16(7): 2085-2094.

Price K, Jackson C R, Parker A J. 2010. Variation of surficial soil hydraulic properties across land uses in the southern Blue Ridge Mountains, North Carolina, USA. Journal of Hydrology, 383(3-4): 256-268.

Ries J B, Hirt U. 2008. Permanence of soil surface crusts on abandoned farmland in the Central Ebro Basin/Spain. CATENA, 72(2): 282-296.

Shi H, Shao M A. 2000. Soil and water loss from the Loess Plateau in China. Journal of Arid Environments, 45(1): 9-20.

Tejedor M, Neris J, Jiménez C. 2013. Soil properties controlling infiltration in volcanic soils (Tenerife, Spain). Soil Science Society of America Journal, 77(1): 202-212.

Vandervaere J P, Vauclin M, Elrick D E. 2000. Transient flow from tension infiltrometers: II. Four methods to determine sorptivity and conductivity. Soil Science Society of America Journal, 64(4): 1272-1284.

Wang B, Liu G B, Xue S, et al. 2011. Changes in soil physico-chemical and microbiological properties during natural succession on abandoned farmland in the Loess Plateau. Environmental Earth Sciences, 62(5): 915-925.

Wang B, Zhang G H, Shi Y Y, et al. 2013. Effect of natural restoration time of abandoned farmland on soil detachment by overland flow in the Loess Plateau of China. Earth Surface Processes and Landforms, 38(14): 1725-1734.

Wang Y H, Yu P T, Feger K H, et al. 2011. Annual runoff and evapotranspiration of forestlands and non-forestlands in selected basins of the Loess Plateau of China. Ecohydrology, 4(2): 277-287.

Wang Z Q, Liu B Y, Liu G, et al. 2009. Soil water depletion depth by planted vegetation on the Loess Plateau. Science in China Series D: Earth Sciences, 52(6): 835-842.

Williams J D, Dobrowolski J P, West N E. 1999. Microbiotic crust influence on unsaturated hydraulic conductivity. Arid Soil Research and Rehabilitation, 13(2): 145-154.

Yüksek T, Yüksek F. 2011. The effects of restoration on soil properties in degraded land in the semi-arid region of Turkey. CATENA, 84(1-2): 47-53.

Yang J L, Zhang G L. 2011. Water infiltration in urban soils and its effects on the quantity and quality of runoff. Journal of Soils and Sediments, 11(5): 751-761.

Zhang X P, Zhang L, McVicar T R, et al. 2008. Modelling the impact of afforestation on average annual streamflow in the Loess Plateau, China. Hydrological Processes, 22(12): 1996-2004.

Zhao X N, Wu P T, Gao X D, et al. 2014. Changes of soil hydraulic properties under early-stage natural vegetation recovering on the Loess Plateau of China. CATENA, 113: 386-391.

Zhao Y G, Wu P T, Zhao S W, et al. 2013. Variation of soil infiltrability across a 79-year chronosequence of naturally restored grassland on the Loess Plateau, China. Journal of Hydrology, 504: 94-103.

Zhou X, Lin H S, White E A. 2008. Surface soil hydraulic properties in four soil series under different land uses and their temporal changes. CATENA, 73(2): 180-188.

Zuo X A, Zhao X Y, Zhao H L, et al. 2009. Spatial heterogeneity of soil properties and vegetation-soil relationships following vegetation restoration of mobile dunes in Horqin Sandy Land, northern China. Plant and Soil, 318(1-2): $153-167$. 